\title{
Early evening prolactin rise in women with regular cycles
}

\author{
K. H. Tennekoon and E. A. Lenton \\ University Department of Obstetrics and Gynaecology, Jessop Hospital for Women, \\ Sheffield S3 7RE, U.K.
}

\begin{abstract}
Summary. Prolactin concentrations were measured in hourly integrated blood samples collected over $24 \mathrm{~h}$ in normally cyclic women during the follicular $(\mathrm{N}=8)$ and the luteal $(\mathbf{N}=7)$ phases of the menstrual cycle. Prolactin concentrations were increased during the evening in all the subjects when compared with the rest of the day-time wake-period. This rise was unrelated to sleep, and peak concentrations were seen at $20: 00 \mathrm{~h}$. During the luteal phase the magnitude of this evening rise of prolactin was significantly greater $(P<0.02$ at 19:00 h and $P<0.001$ at 20:00 h) when compared with the follicular phase, and was only slightly smaller than the magnitude of the sleepinduced prolactin rise. It is therefore suggested that there may be an intrinsic rhythm in prolactin secretion apart from the sleep-induced rise.
\end{abstract}

\section{Introduction}

The pulsatile nature of prolactin release and a sleep-dependent nocturnal rise in prolactin concentrations have been well documented for man (Sassin, Frantz, Weitzman \& Kapen, 1972; Sassin, Frantz, Kapen \& Weitzman, 1973; Parker, Rossman \& Vanderlaan, 1973). These investigators observed a rise in prolactin concentrations within $90 \mathrm{~min}$ of sleep onset. Prolactin levels continued to rise throughout the sleep, reaching maximum concentrations in the early morning hours. On awakening prolactin concentrations decreased rapidly to reach minimum concentrations between 10:00 and 12:00 h. Studies carried out using sleep deprivation and inversion of the sleep-wake cycle confirmed this sleep-dependent nature of the nocturnal rise of prolactin. A rise of prolactin concentrations associated with day-time naps was also observed (Sassin et al., 1973; Parker et al., 1973). In addition to these findings, Sassin et al. (1973) reported a regular significant rise of prolactin at about 18:00 h and a smaller rise at 13:00 $\mathrm{h}$ which were unrelated to sleep. However, this observation does not appear to have been followed further. Apart from the sleep-dependent rise of prolactin, a cyclic variation in prolactin secretion throughout the menstrual cycle was reported by some investigators (Franchimont et al., 1976; Vekemans, Delvoye, L'Hermite \& Robyn, 1977) although this was disputed by others (Tyson \& Friesen, 1973; McNeilly $\&$ Chard, 1974). The present study was designed to examine the $24-\mathrm{h}$ profile of prolactin secretion during the follicular and the luteal phases of the menstrual cycle.

\section{Materials and Methods}

Subjects. Twelve volunteers who were known to have regular, apparently ovulatory, cycles were recruited for this study and their informed consent was obtained. The length of the basal menstrual cycles varied from 26 to 31 days. The stage of the menstrual cycle was determined from basal body temperature records and menstrual dates. The mid-luteal phase was confirmed by plasma progesterone estimations. Four subjects were studied during both the follicular (between Days 3 and 10, Day 1 being the first day of menstrual bleeding) and luteal (between Days 17 and 27) 
phases. The remaining 8 subjects were studied only once during either the follicular (between Days 6 and 11) or the luteal (between Days 18 and 21) phase. Subjects were admitted to hospital for the 24-h study period, during which they remained in bed, received standard hospital meals at 08:00, $12: 30$ and $18: 00 \mathrm{~h}$ and were not on any medication. It was not possible to provide identical meals for each subject and the protein and fat contents were not estimated. They were not allowed to sleep during the day-time and the nocturnal sleep was recorded by an observer who checked the subjects every $30 \mathrm{~min}$ to note whether their eyes were closed and whether they responded in any way to her presence. Although somewhat subjective, the observer's impression of sleep duration generally agreed well with the subject's own comments obtained next day. A 4-ml sample of venous blood was collected every hour for $24 \mathrm{~h}$ from a forearm vein using a double lumen catheter connected to an exfusion pump (Singleton, Adams, Lenton \& Cooke, 1977). This permitted collection of continuous blood samples fractionated at hourly intervals (Kowarski, Thompson, Migeon \& Blizzard, 1971) and so gives a sample which will be less influenced by short-term variations in prolactin concentration. Plasma was separated within $1 \mathrm{~h}$ and stored at $-20^{\circ} \mathrm{C}$ until prolactin concentrations were measured by radioimmunoassay. All the samples from a particular subject were analysed within the same assay.

Assay. The prolactin radioimmunoassay has been described previously (Lenton, Brook, Sobowale \& Cooke, 1979). The First International Reference Preparation (MRC 75/504) was used as the standard supplied by the World Health Organisation through the National Institute for Biological Standards and Control in London. Sensitivity of the assay was $25 \mathrm{mi} . \mathrm{u} . / \mathrm{l}$. Intra-assay coefficient of variation was $4.0 \%$ while inter-assay coefficient of variation was $9.3 \%$.

Calculations. The distribution of peripheral prolactin concentrations in different individuals is non-Gaussian (Lenton et al., 1979). Therefore, geometric means (with appropriate confidence limits) were used to describe group data. Friedman's two-way analysis of variance was used to show any statistically significant difference in prolactin concentration during the day-time wake period (which was defined as the period from 10:00 h until the onset of sleep). A Mann-Whitney U test was used to show any statistically significant difference in evening prolactin concentrations (18:00 to $24: 00 \mathrm{~h}$ ) between the two groups.

\section{Results}

In all the subjects prolactin concentrations were increased during the evening and this rise was separated from the sleep surge by a nadir which generally occurred just before 24:00 $\mathrm{h}$. This effect is shown in Text-fig. 1 which illustrates the 24 -h profile of prolactin of one subject who was studied during both the follicular and luteal phases. During each phase prolactin concentrations were relatively low between $11: 00$ and $16: 00 \mathrm{~h}$ but then began to rise, reaching peak concentrations between 20:00 and 21:00 h. This rise was separated from the sleep surge by a nadir at 23:00 h. With the onset of sleep, prolactin concentrations again rose rapidly to reach peak concentrations between $06: 00$ and $07: 00 \mathrm{~h}$, then decreased gradually over several hours.

In all the subjects studied the sleep-associated nocturnal rise of prolactin was clearly evident and this was generally greater than the evening rise although in 2 subjects studied during the luteal phase the nocturnal prolactin concentrations were only slightly greater than mid-evening concentrations. There was no consistent relationship in the magnitude of the sleep-related surge with the stage of the menstrual cycle when the two groups were compared although 3 out of the 4 subjects studied during both phases had higher prolactin concentrations during the luteal phase. In the remaining subject the follicular-phase sleep surge was twice as great as the luteal-phase sleep surge.

Prolactin concentrations over $24 \mathrm{~h}$ in the follicular and the luteal phases are shown in Text-fig. 2. Friedman two-way analysis of variance applied to prolactin concentrations over the interval 


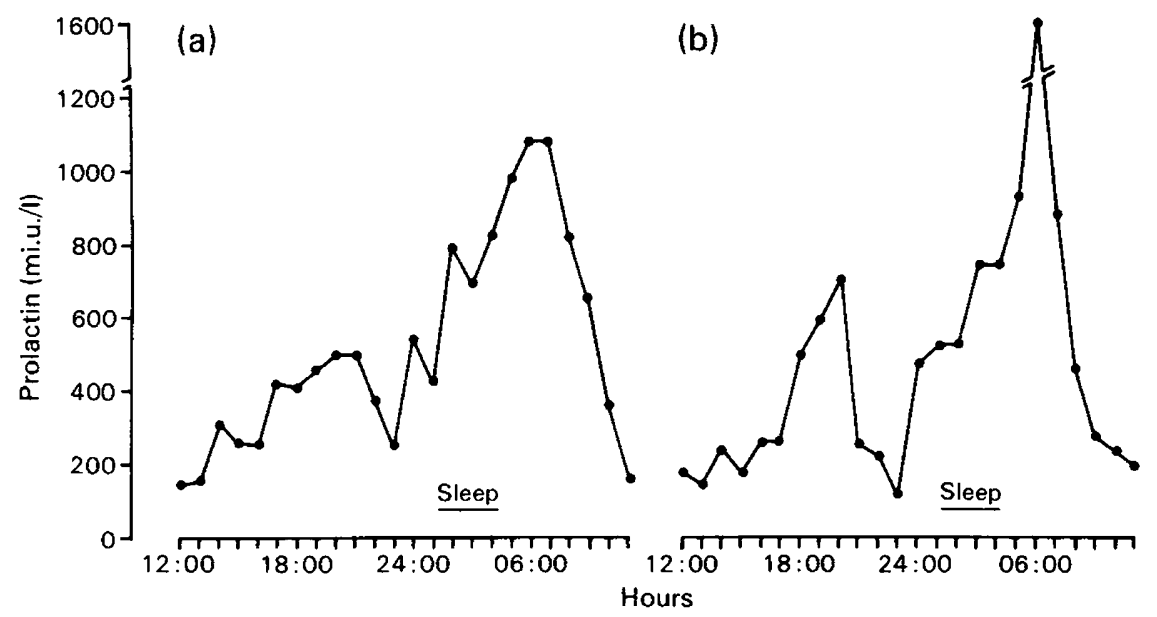

Text-fig. 1. Prolactin concentrations over $24 \mathrm{~h}$ in a normally cyclic woman during (a) the follicular phase and (b) the luteal phase. The duration of sleep is indicated.
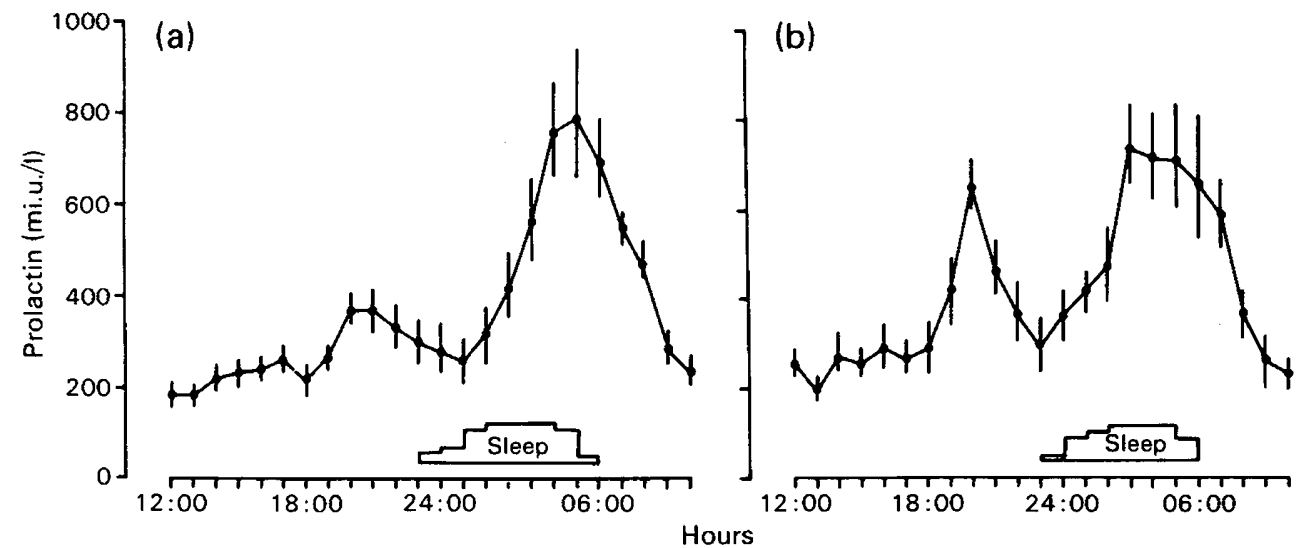

Text-fig. 2. Geometric mean \pm s.e.m. prolactin concentrations over $24 \mathrm{~h}$ (a) during the follicular phase $(\mathrm{N}=8)$ and $(b)$ during the luteal phase $(\mathrm{N}=7)$ in normally cyclic women. The histograms indicate the sleep patterns and are directly proportional to the number of subjects asleep.

11:00-23:00 h revealed significant differences in prolactin concentrations $(P<0.05$ and $P<$ $0.001)$ during the follicular and luteal phases respectively. The evening prolactin rise was significantly greater during the luteal phase $(P<0.02$ at 19:00 h and $P<0.001$ at 20:00 h) than during the follicular phase, when the Mann-Whitney $U$ test was used to compare the magnitude of the early evening prolactin rise between the two groups.

\section{Discussion}

The episodic nature of prolactin release and the sleep-dependent nocturnal rise in prolactin concentrations have been observed by several investigators (see 'Introduction'). However, Desir $e t$ al. (1982) observed a rise in prolactin concentrations at the time of the anticipated sleep rather than 
during actual sleep when they studied prolactin concentrations after jet lag. This led them to postulate that there might be an intrinsic circadian rhythm responsible for the nocturnal rise of prolactin in addition to sleep. Sleep-unrelated diurnal peaks of prolactin have also been reported for the rhesus monkey at 08:45 and 16:30 h (Quabbe, Bumke-Vogt, Gregor, Stolz \& Witt, 1982).

We have attempted to clarify the $24-\mathrm{h}$ profile of prolactin during the follicular and luteal phases of normally cyclic women. Integrated hourly blood sampling was used to smooth out short-term variations in prolactin concentrations. In all our subjects a significant rise in prolactin was seen during the evening. This was unrelated to sleep, generally started between 17:00 and 18:00 h, reached peak concentrations between $20: 00$ and $21: 00 \mathrm{~h}$ and decreased to a nadir by $24: 00 \mathrm{~h}$. The evening rise of prolactin was signficantly greater during the luteal phase than during the follicular phase.

In addition to an early evening rise in prolactin concentrations, all subjects demonstrated a nocturnal sleep-associated prolactin surge (Sassin et al., 1972, 1973; Parker et al., 1973). The magnitude of this prolactin surge was generally greater than the evening rise except in a few subjects studied during the luteal phase. Maximum prolactin concentrations during nocturnal sleep were seen towards the end of the sleep period in most of the subjects. On awakening, the sleepinduced high prolactin concentrations did not return to normal immediately but declined gradually over a period of several hours. Lowest prolactin concentrations were seen between 11:00 and 18:00 $\mathrm{h}$ in most subjects.

Sassin et al. (1973) observed a significant rise of prolactin between 18:00 and 19:00 h whereas in our study peak concentrations of the evening prolactin surge were seen between 20:00 and $21: 00$ h. Sassin et al. (1973) also observed a smaller rise of prolactin between 13:00 and 14:00 h and suggested that both this and the rise of prolactin between 18:00 and 19:00 could be related to meals. Ishizuka, Quigley \& Yen (1983) have demonstrated a meal-related rise in prolactin in normal men which was greater after the mid-day meal than after breakfast. Similarly, Quigley, Ropert \& Yen (1981) have reported a greater increase of prolactin after meal ingestion at 12:00 h than in the evening in normally cyclic, fasting women. Ishizuka et al. (1983) observed that proteins and fats were potent stimulators of prolactin release while carbohydrates had hardly any effect on prolactin release. All our subjects received 3 main meals in the hospital and we failed to observe any significant rise of prolactin following either breakfast or lunch. The composition of the evening meal is unlikely to have been responsible for the evening rise of prolactin as this is generally a light meal and does not contain more fat or protein than either breakfast or lunch.

In the present study we observed a clear rise of prolactin during the evening both during the follicular and the luteal phases. This rise was not related to sleep, and does not appear to be related to the evening meal and it is possible that this may indicate an intrinsic circadian rhythm in prolactin secretion in normally cyclic women. Early morning blood samples, e.g. at 08:30 h are likely to have high prolactin concentrations regardless of the stress because the nocturnal sleeprelated prolactin surge takes a few hours to return to normal. Similarly, evening blood samples may also have higher prolactin concentrations due to the evening prolactin surge. It is therefore necessary to choose the correct time of the day (preferably between 10:00 $\mathrm{h}$ and mid-day meal) when obtaining blood samples for prolactin measurement. Furthermore, if valid comparisons are to be made between prolactin concentrations between subjects or on different days within a subject it is necessary to obtain blood samples at approximately the same time each day.

We thank Kerry Cripps for technical assistance and Gill Store for secretarial assistance.

\section{References}

Desir, D., Cauter, E.V., L'Hermite, M. Refetoff, S., Jadot, C., Caufriez, A., Copinschi, G. \& Robyn, C. (1982) Effects of 'jet lag' on hormonal patterns III
Demonstration of an intrinsic circadian rhythmicity in plasma prolactin. J. clin. Endocr. Metab. 55, 849857. 
Franchimont. P., Dourcy, C., Legrus, J., Reuter, A., Vrindts-Grevaert, Y., Cauwenberge, J. \& Gaspard, $U$. (1976) Prolactin levels during the menstrual cycle. Clin. Endocrin. 5, 643-650.

Ishizuka, B., Quigley, M.E. \& Yen, S.S.C. (1983) Pituitary hormone release in response to food ingestion: evidence for neuroendocrine signals from gut to brain. J. clin. Endocr. Metab. 57, 1111-1116.

Kowarski, A., Thompson, R.G., Migeon, C.J. \& Blizzard, R.M. (1971) Determination of integrated plasma concentrations and true secretion rates of human growth hormone. J. clin. Endocr. Metab. 32, 356-360.

Lenton, E.A., Brook, L.M., Sobowale, O. \& Cooke, I.D. (1979) Prolactin concentrations in normal menstrual cycles and conception cycles. Clin. Endocrin. 10, 383391.

McNeilly, A.S. \& Chard, T. (1974) Circulating levels of prolactin during the menstrual cycle. Clin. Endocrin. 3, 105-112.

Parker, D.C., Rossman, L.G. \& Vanderlaan, E.-F. (1973) Sleep related nyctohemeral and briefly episodic variation in human plasma prolactin concentrations. J. clin. Endocr. Metab. 36, 1119-1124.

Quabbe, H.-J., Bumke-Vogt, C., Gregor, M., Stolz, B. \& Witt, I. (1982) 24 hour pattern of plasma prolactin in the male rhesus monkey and its relation to the sleep/wake cycle. Endocrinology 110, 969-975.
Quigley, M.E., Ropert, J.F. \& Yen, S.S.C. (1981) Acute prolactin release triggered by feeding. J. clin. Endocr. Metab. 52, 1043-1045.

Sassin, J.F., Frantz, A.G., Weitzman, E.D. \& Kapen, S. (1972) Human prolactin: 24 hour pattern with increased release during sleep. Science, N.Y. 177, 1205-1207.

Sassin, J.F., Frantz, A.G., Kapen, S. \& Weitzman, E.D. (1973) The nocturnal rise of human prolactin is dependent on sleep. J. clin. Endocr. Metab. 37, 436440.

Singleton, G.H., Adams, M., Lenton, E.A. \& Cooke, I.D. (1977) Continuous exfusion of blood and its subsequent fractionation in the human. In Physical Science Techniques in Obstetrics and Gynaecology, pp. 130135. Ed. M. Black \& M. English. Pitman Medical Publication, Tunbridge Wells.

Tyson, J. \& Friesen, H. (1973) Factors influencing the secretion of human prolactin and growth hormone in menstrual and gestational women. Am. J. Obstet. Gynec. 116, 377-378.

Vekemans, M., Delvoye, P., L'Hermite, M. \& Robyn, C. (1977) Serum prolactin levels during the menstrual cycle. J. clin. Endocr. Metab. 44, 989-993.

Received 30 July 1984 